\title{
APRENDIZAGEM BASEADA EM PRÁTICA: ENTRE REMÉDIOS E RECEITAS EM PEQUENA FARMÁCIA
}

DOI: 1014211/regepe.v5i3.388

Artigo recebido em: 30/06/2016

Artigo aprovado em: 30/06/2016

Danieli Gugel de Oliveira - Universidade de Passo Fundo - UPF ${ }^{1}$ Anelise Rebelato Mozzato - Universidade de Passo Fundo - UPF ${ }^{2}$

Daniela Siqueira Colet - Universidade de Passo Fundo - UPF

Resumo: Este artigo versa sobre a temática da aprendizagem organizacional (AO), visando melhor compreensão sob a perspectiva sociológica. Apresenta-se como objetivo: compreender 0 processo de aprendizagem (individual, grupal, organizacional e interorganizacional) dos trabalhadores de uma farmácia, sob a perspectiva da $\mathrm{AO}$ baseada em prática (perspectiva sociológica). Para tanto, realizou-se uma pesquisa exploratória do tipo estudo de caso e com abordagem qualitativa dos dados em uma farmácia de pequeno porte, localizada no norte do Rio Grande do Sul. O estudo permitiu identificar que nessa farmácia, a aprendizagem acontece nos quatro níveis do continuum da aprendizagem, no fluxo das atividades relacionais cotidianas, de acordo com os preceitos dos estudos da $A O$, baseada na perspectiva prática. As conclusões revelam que o estudo de caso traz contribuições importantes em razão de exemplificar claramente o processo da $A O$ e também da aprendizagem interorganizacional (AIO), na perspectiva baseada em prática.

Palavras-chave: Aprendizagem Organizacional; Níveis de Aprendizagem; Perspectiva Sociológica.

\section{LEARNING BASED ON PRACTICE: BETWEEN REMEDIES AND REVENUE SMALL PHARMACY}

Abstract: This article deals with the theme of organizational learning $(O A)$, with the aim of better understanding from a sociological perspective. Its objective is: to understand the process of learning (individual, group, organizational and interorganizational) of employees of a pharmacy, from the perspective of OA based

\footnotetext{
1 Endereço: Universidade de Passo Fundo - UPF. BR 285, São José. Passo Fundo - RS, CEP: 99052-900. E-mail: dani.digo2010@hotmail.com

2 E-mail: anerebe@upf.br

${ }^{3}$ E-mail: danicolet@hotmail.com
}

OLIVEIRA, D. G.; MOZZATO, A. R., COLET, D. S. Aprendizagem baseada em prática entre remédios e receitas em pequena farmácia. Revista de Empreendedorismo e Gestão de Pequenas Empresas, v.5, n.3, 2016. 
on practice (sociological perspective). Therefore, there was an exploratory research of the case study type with a qualitative approach in a small pharmacy located in north of Rio Grande do Sul. The study revealed that this pharmacy, the learning takes place in the four levels of continuum of learning, in the flow of everyday relational activities, according to the precepts of the OA studies, based on practice perspective. The findings evidence that the case study brings important contributions due to clearly illustrate the OA process and the interorganizational learning (IOL) in perspective based on practice.

Keywords: Organizational Learning; Levels of Learning; Sociological Perspective.

\section{Introdução}

Este artigo versa sobre a temática aprendizagem organizacional (AO), visando uma compreensão melhor sob a perspectiva sociológica. Tal perspectiva entende a aprendizagem por meio das construções sociais que se dão no todo relacional do dia a dia (GHERARDI; NICOLINI; ODELLA, 1998; LAVE; WENGER, 1991; GHERARDI; NICOLINI, 2001; GHERARDI, 2001, 2008, 2009a, 2009b, 2012; CORRADI; GHERARDI; VERZELLONI, 2010; GHERARDI; SOUTO, 2013; GHERARDI, 2015). Assim, tem-se como objetivo compreender o processo de aprendizagem (individual, grupal, organizacional e interorganizacional) dos trabalhadores de uma pequena farmácia sob a perspectiva da $\mathrm{AO}$ baseada em prática.

As teorias baseadas em práticas evidenciam que a aprendizagem não pode ser considerada somente como um processo individual, uma vez que emerge de relações e interações das pessoas com os elementos sociais e materiais de contextos particulares, tendo em vista que o local trabalho é um espaço de produção contínua de conhecimento (GHERARDI, 2009; FLACH; ANTONELLO, 2011; GHERARDI; SOUTO, 2013). Portanto, os indivíduos são sujeitos primários de aprendizagem nas organizações, sendo que são eles quem criam as formas organizacionais que permitem a aprendizagem, de tal modo, facilitando a transformação organizacional (DOGSON, 1993).

Pode-se dizer que a $A O$ é multinível, tendo em vista que o fenômeno depende do aprendizado constatado nos níveis de indivíduo, grupo, organizacional e

OLIVEIRA, D. G.; MOZZATO, A. R., COLET, D. S. Aprendizagem baseada em prática entre remédios e receitas em pequena farmácia. Revista de Empreendedorismo e Gestão de Pequenas Empresas, v.5, n.3, 2016. 
interorganizacional (ANTONELLO; GODOY, 2011; NOGUEIRA; ODELIUS, 2015). Desse modo, por mais que se tenha avançado nos estudos sobre o processo da aprendizagem nos quatro níveis, e que diferentes autores (CROSSAN et al., 1995; CROSSAN; LANE; WHITE, 1999; DIERKES et al., 2001; EASTERBY-SMITH; BURGOYNE; ARAUJO, 2001; EASTERBY-SMITH; LYLES, 2003; ANTONELLO; GODOY, 2011; CROSSAN; MAURER; WHITE, 2011; MOZZATO; BITENCOURT, 2014) tenham trazido contribuições importantes para estudos do tema, eles mesmos apontam para a necessidade de mais pesquisas, sobretudo empíricas. Além do mais, entende-se como necessário os estudos sobre a $A O$ sob outras perspectivas, principalmente as de cunho menos utilitarista como, por exemplo, a abordagem baseada em prática que pode contribuir para o melhor entendimento da $A O$.

Dado o contexto, justifica-se a realização deste artigo com base no estudo de um caso único, o qual tem como questão de pesquisa: tendo como base a abordagem da $\mathrm{AO}$ baseada em prática, como ocorre o processo de aprendizagem (individual, grupal, organizacional e interorganizacional) na farmácia pesquisada? Entende-se que com esta pesquisa empírica se está contribuindo para com o avanço do conhecimento existente sobre $A O$ nos estudos organizacionais, uma vez que se contempla uma perspectiva analítica menos explorada (AO baseada em prática).

Corroborando com essa perspectiva, Bispo (2013) aponta como necessário mais estudos com abordagem empírica nesta perspectiva sociológica, visando à evolução desse paradigma emergente no contexto nacional, visto que o contexto internacional já avança. Ainda justificando a pertinência dessa lente teórica, cita-se como exemplo a recente publicação internacional de Billett, Harteis e Gruber (2014): International Handbook of Research in Professional and Practice-based Learning.

Este artigo está organizado em seções. Após esta introdução apresenta-se a segunda seção com a fundamentação teórica sobre $A O$, incluindo a abordagem baseada em práticas. Na terceira seção, apresenta-se a metodologia delineada. A análise dos dados sob a perspectiva da $\mathrm{AO}$ baseada em prática é apresentada na seção quatro. Por fim, são tecidas as considerações finais provenientes deste estudo, incluindo sugestões que possam contribuir com melhorias no campo empírico pesquisado, principalmente no meio acadêmico.

OLIVEIRA, D. G.; MOZZATO, A. R., COLET, D. S. Aprendizagem baseada em prática entre remédios e receitas em pequena farmácia. Revista de Empreendedorismo e Gestão de Pequenas Empresas, v.5, n.3, 2016. 


\section{Retomando Aspectos Teóricos sobre a Aprendizagem Organizacional}

As discussões sobre $A O$ têm ganhado espaço ao longo dos últimos 40 anos (ANTONELLO; GODOY, 2011; RODRIGUES; AZEVEDO, 2013; BISPO, 2013; NOGUEIRA; ODELIUS, 2015), apresentando um crescimento exponencial a partir dos anos 90 (ANTONELLO; GODOY, 2010, 2011). Antonacopoulou evidencia que os principais pesquisadores sobre o tema tendem a argumentar que as organizações

[...] desenvolvem e acumulam conhecimentos em arquivos, regras, papéis, rotinas, procedimentos, e através de sua cultura, e na estrutura. As organizações desenvolvem e compartilham modelos mentais, valores e comportamentos, que constituem parte da memória organizacional. (ANTONACOPOULOU, 2006, p. 456).

A partir dessa perspectiva, a $\mathrm{AO}$ pode existir quando se considera que as organizações não têm cérebros, mas sistemas cognitivos e memórias que thes permitem dar sentido às mudanças no seu ambiente organizacional de aprendizagem.

Antonello e Godoy (2011) explicitam que existem inúmeros enfoques e lentes teóricas para estudar a aprendizagem, tais como: psicológica, sociológica, antropológica, da ciência política, histórica, econômica e da ciência da administração. Evidencia-se que, neste estudo, trabalha-se com a lente teórica da sociologia. As autoras consideram assustador revisar a literatura no que diz respeito aos conceitos de $\mathrm{AO}$, em virtude da abrangência de ideias que podem ser julgadas relevantes. Dada tal abrangência, apresentam-se alguns conceitos mais claros e definidores sobre $\mathrm{AO}$, sobretudo para a abordagem desta pesquisa.

Bastos, Gondin e Loiola (2004, p. 224) afirmam que a AO começa acontecer quando os integrantes da organização começam a dividir suas práticas, ou seja:

[...] no momento em que a organização tem a capacidade de disseminar e favorecer o compartilhamento de estruturas cognitivas e de modelos interpretativos, e consequentemente, é capaz de criar uma unidade de significado mais ou menos comum dos eventos que ocorrem neste contexto.

OLIVEIRA, D. G.; MOZZATO, A. R., COLET, D. S. Aprendizagem baseada em prática entre remédios e receitas em pequena farmácia. Revista de Empreendedorismo e Gestão de Pequenas Empresas, v.5, n.3, 2016. 
Para Bitencourt (2001), AO consiste no desenvolvimento contínuo de estratégias e procedimentos para que se atinja melhores resultados, necessitando da participação efetiva das pessoas no processo de aquisição e disseminação de conhecimento.

Não obstante, Zangiski, Lima e Costa (2009) afirmam que existem muitos fatores que podem influenciar o ciclo de $\mathrm{AO}$, especialmente aqueles ligados à cultura organizacional, como crenças e valores da organização. "Tais fatores podem configurar-se como barreiras ao processo de aprendizagem e, consequentemente, à formação de competências nas empresas" (ZANGISKI; LIMA; COSTA, 2009, p. 65). Aspectos mais específicos da $A O$, em uma perspectiva multinível são mais bem detalhados na sequência.

\section{Aprendizagem Organizacional: Perspectiva Multinível}

Entende-se que perspectiva multinível da $\mathrm{AO}$ é composta por quatro níveis: individual, grupal, organizacional e interorganizacional. No entanto, esse quarto nível, por mais que já tenha sido mencionado na literatura internacional no final do século passado (CROSSAN et al., 1995; INKPEN, 1998; LARSSON et al., 1998), é nesse século que ele é mais reconhecido e bem trabalhado tanto por pesquisadores internacionais como nacionais, tais como: Knight (2002), Knight e Pye (2005), Wegner (2011), Mozzato e Bitencourt (2014) e Mozzato, Bitencourt e Grzybovski (2015).

$\mathrm{Na}$ lógica do ciclo da $\mathrm{AO}$, ainda sem a inclusão da aprendizagem interorganizacional (AIO), Schikmann (2003, p. 32) apresenta um quadro (Quadro 1) com uma síntese das principais características dos processos de intuição, interpretação, integração e institucionalização, com base no framework proposto por Crossan, Lane e White (1999).

OLIVEIRA, D. G.; MOZZATO, A. R., COLET, D. S. Aprendizagem baseada em prática entre remédios e receitas em pequena farmácia. Revista de Empreendedorismo e Gestão de Pequenas Empresas, v.5, n.3, 2016. 


\section{QUADRO 1 - SÍNTESE DAS PRINCIPAIS CARACTERÍSTICAS DOS PROCESSOS DE} APRENDIZAGEM

\begin{tabular}{|c|c|c|}
\hline Processo & & Características \\
\hline Intuição & $\begin{array}{l}\text { É o processo subconsciente } \\
\text { de desenvolvimento de } \\
\text { insights }\end{array}$ & $\begin{array}{l}\text { Este termo, usado em situação empresarial, está } \\
\text { relacionado com inovação e mudança; está } \\
\text { orientado à possibilidade futura e apoia a } \\
\text { pesquisa de novos caminhos. }\end{array}$ \\
\hline Interpretação & $\begin{array}{l}\dot{E} \text { a busca dos elementos } \\
\text { conscientes do processo de } \\
\text { aprendizagem individual; } \\
\text { focaliza a mudança no } \\
\text { entendimento e as ações do } \\
\text { indivíduo }\end{array}$ & $\begin{array}{l}\text { Desenvolvimento de mapas cognitivos; a } \\
\text { linguagem tem papel essencial; os indivíduos } \\
\text { podem fazer conexões explícitas; permite que os } \\
\text { indivíduos desenvolvam um sentido de } \\
\text { entendimento compartilhado; é uma atividade } \\
\text { social que cria e refina a linguagem comum, } \\
\text { clarifica as imagens e cria significados } \\
\text { compartilhados. }\end{array}$ \\
\hline Integração & $\begin{array}{l}\dot{E} \quad 0 \quad \text { compartilhamento do } \\
\text { entendimento }\end{array}$ & $\begin{array}{l}\text { O foco é uma ação coletiva; a linguagem ajuda a } \\
\text { preservar o que foi aprendido; através do diálogo } \\
\text { o grupo desenvolve significados compartilhados } \\
\text { novos e mais profundos. }\end{array}$ \\
\hline $\begin{array}{l}\text { Institucionali- } \\
\text { zação }\end{array}$ & $\begin{array}{l}\text { É a captura e formalização dos } \\
\text { padrões de interação que } \\
\text { alavancam a aprendizagem } \\
\text { individual dos membros da } \\
\text { organização }\end{array}$ & $\begin{array}{l}\text { A aprendizagem é inserida nos sistemas, } \\
\text { estruturas, estratégia, rotinas, práticas prescritas, } \\
\text { sistemas de informação e infraestrutura; os } \\
\text { planos e sistemas formais ajudam a ter ações } \\
\text { coerentes; contribui para operações mais } \\
\text { eficientes. }\end{array}$ \\
\hline
\end{tabular}

FONTE: Schikmann (2003, p. 32).

Quanto aos os fatores que facilitam e dificultam o processo de aprendizagem organizacional, Antonacopoulou (2001) argumenta que podem ser tanto organizacionais como pessoais. Os fatores que facilitam a $\mathrm{AO}$ incidem em proporcionar novas experiências, desafiar as maneiras tradicionais de fazer as coisas, proporcionar e facilitar o uso de treinamento, encorajar a revisão e o planejamento de atividades de aprendizagem e proporcionar feedback. Já os fatores que dificultam a AO são: valores culturais e crenças, cultura e clima organizacional, comunicação e feedback, processos de tomada de decisão e capacidade intelectual/mental dos trabalhadores. Em suma, a aprendizagem parte do individual, passa para o grupal, possibilitando a AO.

Na perspectiva multinível, como salientam Larsson et al. (1998), Knight e Pye (2005), e também Mozzato e Bitencourt (2014), tem possibilidade de se passar para o quarto nível da aprendizagem, a AIO. Este último nível da aprendizagem, a AIO é explicitada no continuum da aprendizagem por Mozzato e Bitencourt (2014) e Mozzato, Bitencourt e Grzyboviski (2015), também tendo como base o framework de

OLIVEIRA, D. G.; MOZZATO, A. R., COLET, D. S. Aprendizagem baseada em prática entre remédios e receitas em pequena farmácia. Revista de Empreendedorismo e Gestão de Pequenas Empresas, v.5, n.3, 2016. 
Crossan, Lane e White (1999). O nível interorganizacional, com base em Larsson et al. (1998), é entendido como a troca de conhecimentos entre diferentes organizações por meio da interação e cooperação.

Greve (2005) aponta que a AlO difere dos outros níveis de aprendizagem, pois nela aprende-se com as experiências de outras organizações, externamente por intermédio de indivíduos e não com ela própria, como acontece em outros níveis. Por meio da $\mathrm{AlO}$ as pessoas interagem além das fronteiras organizacionais por meio da cooperação, esta última enfatizada por Mozzato e Bitencourt (2014) neste nível de aprendizagem. Após essa análise multinível da aprendizagem, parte-se para o entendimento da $\mathrm{AO}$ baseada em prática.

\section{Aprendizagem Organizacional Baseada em Prática}

A AO trabalhada com a abordagem sociológica sob a perspectiva baseada em prática, constitui-se em importante lente teórica (GHERARDI; NICOLINI; ODELLA, 1998; LAVE; WENGER, 1991; GHERARDI; NICOLINI, 2001; NICOLINI; GHERARDI; YANOW, 2003; GHERARDI, 2001, 2008, 2009a, 2009b, 2012; CORRADI; GHERARDI; VERZELLONI, 2010; GHERARDI; SOUTO, 2013; BILLETT; HARTEIS; GRUBER, 2014; GHERARDI, 2015). Tal perspectiva entende a aprendizagem por meio das construções sociais que se dão no todo relacional do dia a dia, de maneira dinâmica e contínua.

Na lógica da AO baseada em prática, Feitoza et al. (2006, p. 2) consideram a aprendizagem como sendo:

[...] um processo contínuo e dinâmico, no qual o aprendiz enfrenta criticamente a realidade. Isto significa que a aprendizagem não pode ser considerada apenas como um produto final. A apreensão do conhecimento ocorre a partir da prática e a ela se reverte, ou seja, a teoria e prática estão interligadas.

Antonello e Godoy (2011, p. 573) sustentam que a teoria da aprendizagem baseada em prática não pode ser "um processo apenas individual, pois a aprendizagem é compreendida pelo emergir de relações e interações das pessoas

OLIVEIRA, D. G.; MOZZATO, A. R., COLET, D. S. Aprendizagem baseada em prática entre remédios e receitas em pequena farmácia. Revista de Empreendedorismo e Gestão de Pequenas Empresas, v.5, n.3, 2016. 
com os elementos sociais e materiais de contextos particulares (ambiente, cultura, linguagem, entre outros)".

As abordagens de AO predominantes no Brasil recebem forte influência da administração científica tradicional, ainda que a partir de diversos campos teóricos, sendo que, no geral, as publicações nacionais consideram a aprendizagem como aquisição e aplicação de conhecimento, com mudança observável de comportamentos, ações, resultados, atitudes, etc. (ANTONELLO; GODOY, 2011, p. 573).

Importante dizer que neste trabalho a aprendizagem e o conhecimento são vistos além da cognição, isto é, como atividade inerentemente relacional que ocorre nas interações entre as pessoas nas práticas cotidianas. Nesse sentido, Gherardi (2006, 2009a) salienta que tais práticas acontecem no fluxo das atividades que fazem parte da rotina diária de trabalho, desencadeando a aprendizagem.

Por sua vez, Gherardi (2001) conceitua a prática como a conexão entre o saber e o fazer. Flach e Antonello (2011, p. 163) afirmam que a aprendizagem não pode ser considerada apenas como um processo individual, "a aprendizagem é compreendida pelo emergir de relações e interações das pessoas com os elementos sociais e materiais de contextos particulares".

A participação por meio da prática é uma forma de adquirir o conhecimento em ação, diversificar ou continuar este tipo de conhecimento e de produzir ou reproduzir a sociedade (ANTONELLO; GODOY, 2011). Gherardi (2009b) enfatiza que o conhecimento prático é o pré-requisito para o exercício competente da mesma ação ao longo do tempo e, portanto, para a repetição e reprodução do conhecimento no cotidiano.

Adentrando o terreno da aprendizagem baseada em prática, trazendo conceitos e referências da área, este trabalho segue apresentando o debate acerca da capacidade absortiva relacionada à $A O$.

OLIVEIRA, D. G.; MOZZATO, A. R., COLET, D. S. Aprendizagem baseada em prática entre remédios e receitas em pequena farmácia. Revista de Empreendedorismo e Gestão de Pequenas Empresas, v.5, n.3, 2016. 


\section{A Capacidade Absortiva Relacionada à Aprendizagem}

O debate sobre capacidade absortiva tem crescido desde a década de 90 , com vários pesquisadores chamando atenção para o seu impacto nos resultados da competição baseada em conhecimento (CRUZ, 2011). Para Wegner e Maehler (2012), as organizações valorizam cada vez mais o conhecimento existente dentro ou fora da organização como um componente estratégico para o seu negócio.

Cohen e Levinthal (1990, p. 128) definem a capacidade absortiva como "a habilidade da firma de reconhecer o valor de novas informações externas, assimilálas e aplicá-las aos fins comerciais". A capacidade absortiva de uma organização é a soma das capacidades absortivas de seus trabalhadores. Diante dessa proposição, os autores tratam a capacidade absortiva como facilitadora do processo de aprendizagem, sendo que a capacidade absortiva evidencia característica de cumulatividade, facilitando a aprendizagem de processos posteriores, tanto intra como interorganizacional.

Para Daghfous (2004) a capacidade absortiva possibilita à empresa adquirir e utilizar de forma eficiente o conhecimento externo e interno, responsáveis pela habilidade da empresa em se moldar às mudanças e modernizar-se frente a elas, a fim de permanecer competitiva junto à concorrência. Lane e Lubatkin (1998) afirmam que grande parte dos estudos a respeito de AIO incide sobre a capacidade absortiva, os quais também a tratam como facilitadora do processo da $\mathrm{AIO}$, assim como sustentam Mozzato, Bitencourt e Grzybovski (2015). Cruz (2011, p. 33) apresenta uma síntese das contribuições teóricas mais relevantes referentes à capacidade absortiva, apresentada no Quadro 2. 
QUADRO 2 - DEFINIÇÕES DE CAPACIDADE ABSORTIVA

\begin{tabular}{|c|c|c|}
\hline Autores & $\begin{array}{c}\text { Tipo de } \\
\text { contribuição }\end{array}$ & Detalhamento da contribuição \\
\hline \multirow{5}{*}{$\begin{array}{l}\text { Cohen e Levinthal } \\
\text { (1990) }\end{array}$} & $\begin{array}{c}\text { Primeira } \\
\text { conceituação }\end{array}$ & $\begin{array}{l}\text { "Habilidade coletiva da firma em reconhecer o valor } \\
\text { de um novo conhecimento externo, assimilá-la e } \\
\text { aplicá-lo a fins comerciais" }\end{array}$ \\
\hline & $\begin{array}{l}\text { Definição de dois } \\
\text { antecedentes } \\
\text { organizacionais }\end{array}$ & $\begin{array}{l}\text { O conhecimento prévio da empresa e a condução de } \\
\text { atividades internas de P\&D. }\end{array}$ \\
\hline & $\begin{array}{l}\text { Elementos em } \\
\text { nível individual }\end{array}$ & $\begin{array}{l}\text { - Dependência das capacidades dos empregados e a } \\
\text { interação entre eles pode aumentar a capacidade da } \\
\text { organização de fazer novas associações. }\end{array}$ \\
\hline & $\begin{array}{c}\text { Elementos em } \\
\text { nível } \\
\text { organizacional }\end{array}$ & Rede de comunicação interna e externa. \\
\hline & $\begin{array}{c}\text { Aquisição de CA } \\
\text { em fontes externas }\end{array}$ & $\begin{array}{l}\text { Contratação de novos funcionários ou cooperação } \\
\text { em projetos de } P \& D \text {. }\end{array}$ \\
\hline $\begin{array}{l}\text { Zahra e George } \\
\qquad(2002)\end{array}$ & $\begin{array}{l}\text { Desmembramento } \\
\text { da CA em } \\
\text { dimensões e } \\
\text { componentes }\end{array}$ & $\begin{array}{l}\text { Dimensões: potencial e realizada. } \\
\text { Componentes: } \quad \text { Aquisição, } \\
\text { transformação e exploração. }\end{array}$ \\
\hline Autores & $\begin{array}{c}\text { Tipo de } \\
\text { contribuição }\end{array}$ & Detalhamento da contribuição \\
\hline \multirow[t]{2}{*}{$\begin{array}{l}\text { Zahra e George } \\
(2002)\end{array}$} & $\begin{array}{l}\text { Ampliação do } \\
\text { conceito }\end{array}$ & $\begin{array}{l}\text { "Grupo de rotinas e processos organizacionais pelos } \\
\text { quais as firmas adquirem, assimilam, transformam e } \\
\text { exploram conhecimento para produzir uma } \\
\text { capacidade organizacional dinâmica" }\end{array}$ \\
\hline & $\begin{array}{l}\text { Três fatores } \\
\text { moderadores }\end{array}$ & $\begin{array}{l}\text { Desencadeadores de ativação, mecanismos de } \\
\text { integração social e regime de apropriabilidade. }\end{array}$ \\
\hline $\begin{array}{l}\text { Oswald Jones } \\
\quad(2006)\end{array}$ & $\begin{array}{l}\text { Importância da } \\
\text { gerência }\end{array}$ & $\begin{array}{l}\text { Papel proativo da gerência como agente de } \\
\text { mudança. }\end{array}$ \\
\hline $\begin{array}{l}\text { Easterby-Smith et } \\
\text { al. (2008) }\end{array}$ & Fator mediador & $\begin{array}{l}\text { Influência do poder em processos de aquisição e } \\
\text { exploração do conhecimento }\end{array}$ \\
\hline $\begin{array}{l}\text { Lane, Koka e } \\
\text { Pathak (2006) }\end{array}$ & $\begin{array}{l}\text { Ampliação do } \\
\text { conceito }\end{array}$ & $\begin{array}{l}\text { "Capacidade absortiva é a habilidade da firma de } \\
\text { utilizar conhecimento desenvolvido externamente por } \\
\text { meio de três processos sequenciais: (1) reconhecer e } \\
\text { entender novo conhecimento externo potencialmente } \\
\text { valioso por meio de aprendizado investigativo; (2) } \\
\text { assimilar novo conhecimento assimilado para criar } \\
\text { novo conhecimento e resultados comerciais por meio } \\
\text { de aprendizado exploratório". }\end{array}$ \\
\hline $\begin{array}{l}\text { Veja-Jurado, } \\
\text { Gutiérrez-Garcia e } \\
\text { Fernàndes-de- } \\
\text { Lucio (2008) } \\
\text { Murovec; Prodan, } \\
\text { (2009) }\end{array}$ & $\begin{array}{l}\text { Distinção de tipos } \\
\text { de capacidade } \\
\text { absortiva-industrial } \\
\text { e científica }\end{array}$ & $\begin{array}{l}\text { Capacidade absortiva industrial (aquisição de } \\
\text { conhecimento proveniente de parceiros industriais, } \\
\text { como clientes, concorrentes e fornecedores) e } \\
\text { científica (conhecimento proveniente de } \\
\text { universidades, institutos de tecnologia e centros de } \\
\text { pesquisa privados e públicos). }\end{array}$ \\
\hline
\end{tabular}

FONTE: Cruz (2011, p. 33).

Daghfous (2004) afirma que a base do conhecimento prévio é o primeiro fator a afetar a capacidade absortiva, visto que depende de unidades individuais de conhecimento dentro da organização. O autor ainda cita que uma empresa que

OLIVEIRA, D. G.; MOZZATO, A. R., COLET, D. S. Aprendizagem baseada em prática entre remédios e receitas em pequena farmácia. Revista de Empreendedorismo e Gestão de Pequenas Empresas, v.5, n.3, 2016. 
busca melhorar sua capacidade absortiva investe no desenvolvimento de seus empregados por meio de atividades, como treinamento, não deixando de considerar que a $\mathrm{AO}$ também representa um importante papel no desenvolvimento da capacidade absortiva.

Finalizando esta segunda seção sobre aspectos teóricos da aprendizagem, fica evidenciado que a capacidade absortiva aparece como uma forma de maior aproveitamento dos conhecimentos prévios e ajuda na busca de novos conhecimentos, tanto dentro como fora da organização, facilitando e sendo facilitada pelo processo da aprendizagem.

\section{Procedimentos Metodológicos}

Para a realização deste estudo optou-se por uma pesquisa do tipo qualitativa (DENZIN; LINCOLN, 2000; FLICK, 2009). Quanto ao procedimento técnico, constituiu-se em um estudo de caso, seguindo os procedimentos de Yin (2005).

O local empírico escolhido para este estudo foi uma farmácia de pequeno porte, que comercializa medicamentos em geral, genéricos e similares, além de perfumaria e cosméticos, localizada no interior do Rio Grande do Sul. Tal farmácia possui um total de cinco pessoas envolvidas diretamente no trabalho: o casal proprietário da farmácia e mais três funcionários.

Os critérios para a escolha desta farmácia deram-se em razão da acessibilidade a uma empresa de pequeno porte, visto que a pretensão principal foi a demonstração da aplicabilidade da abordagem teórica da $\mathrm{AO}$ sob a perspectiva baseada na prática. Assim, entende-se que o estudo de caso traz contribuições importantes em razão de exemplificar claramente o processo da aprendizagem em seus diferentes níveis: individual, grupal, organizacional e interorganizacional, sob a perspectiva sociológica da aprendizagem.

Como técnica de coleta de dados primários utilizou-se de entrevista com roteiro semiestruturado e a observação não participante. Nesse período, foram realizadas incursões quinzenais à farmácia, inclusive aos sábados e domingos,

OLIVEIRA, D. G.; MOZZATO, A. R., COLET, D. S. Aprendizagem baseada em prática entre remédios e receitas em pequena farmácia. Revista de Empreendedorismo e Gestão de Pequenas Empresas, v.5, n.3, 2016. 
totalizando doze finais de semana e um total de aproximadamente setenta e duas horas in loco.

As entrevistas-roteiro foram realizadas nas quatro primeiras visitas, sendo que a duração com cada um dos proprietários foi cerca de uma hora e com os funcionários, em torno de trinta minutos. Tanto nessas primeiras incursões no campo de pesquisa como até a última visita, a pesquisadora realizou anotações no caderno de campo tanto das suas observações, quanto de alguns questionamentos que entendeu como oportunos para a melhor compreensão do processo da $A O$, assim como em relação à dinâmica de funcionamento da farmácia. A observação também foi utilizada para confirmar as falas das entrevistas, além de verificar o funcionamento dos processos da farmácia e dos aspectos envolvidos na aprendizagem.

Para o estudo dos dados, utilizou-se a análise de conteúdo de acordo com Bardin (2006), respeitando os preceitos abordados por Mozzato e Grzyboviski (2011) sobre o rigor das análises qualitativas, sobretudo na análise de conteúdo. Nessa lógica apresentada pelas autoras, os dados foram transcritos, codificados de acordo com a abordagem teórica, chegando nas seguintes categorias analíticas: aprendizagem em seus diferentes níveis, abordagem baseada em prática e capacidade absortiva. Realizada a categorização, os dados foram analisados e interpretados à luz do referencial teórico.

\section{O Processo da Aprendizagem na Farmácia Pesquisada: Caracterização do Local e dos Participantes da Pesquisa}

A farmácia estudada é caracterizada como de pequeno porte e localiza-se em uma pequena cidade ao norte do Rio Grande do Sul, possuindo 8 anos de atividades. Anteriormente a este período, a farmácia estava localizada em outra cidade e possuía outros proprietários. Quando a atual proprietária se formou no curso superior em farmácia, começou a trabalhar nessa farmácia e após 1 ano comprou-a. Logo após a compra, fez a mudança da farmácia para a sua cidade natal, trocando o nome do negócio. Como proprietária, iniciou com apenas uma

OLIVEIRA, D. G.; MOZZATO, A. R., COLET, D. S. Aprendizagem baseada em prática entre remédios e receitas em pequena farmácia. Revista de Empreendedorismo e Gestão de Pequenas Empresas, v.5, n.3, 2016. 
funcionária e hoje conta com quatro trabalhadores: o socioproprietário, que é seu marido e faz a gestão da farmácia, e três funcionárias realizam o atendimento.

$\mathrm{Na}$ caracterização dos trabalhadores da farmácia, segue-se com mais algumas descrições sobre os proprietários. Eles são casados, possuem dois filhos e ambos têm 31 anos de idade. Ela é formada em farmácia e ele em educação física. O casal de proprietários trabalha juntos há nove anos. Quanto às funcionárias, duas possuem Ensino Médio completo e são casadas (Atendente 1 e Atendente 3), destas, uma possui uma filha. A Atendente 3 atua no mercado de trabalho há vinte e quatro anos e a Atendente 1 há dezoito anos. A Atendente 2 atua no mercado em questão há três anos. A terceira funcionária (Atendente 2) é solteira, não tem filhos e possui Ensino Superior incompleto em Administração. As idades das atendentes variam entre 20 e 39 anos.

Apenas a Atendente 2 e a proprietária já haviam trabalhado em farmácia anteriormente. A farmacêutica é a pessoa que trabalha há mais tempo na farmácia, estando desde o início de suas atividades, há oito anos. Após essa caracterização, parte-se para a análise das categorias analíticas definidas.

\section{O Processo da Aprendizagem na Farmácia: Análise das Categorias}

\section{Categoria 1: Aprendizagem em seus Diferentes Níveis}

Ciente de que a aprendizagem inicia no nível individual, entende-se como importante salientar a interferência das experiências e formação profissional dos trabalhadores da farmácia.

Quando a farmacêutica começou a trabalhar no ramo não detinha muito conhecimento, em razão de ser recém-formada. No entanto, admite que a aprendizagem ocorrida durante o estágio no período da faculdade the ajudou bastante. Por outro lado, mesmo não tendo conhecimento específico na área de farmácia, tanto a Atendente 1 como o proprietário relatam que experiências anteriores em outras áreas foram válidas. A Atendente 2 já havia trabalhado em uma farmácia e relata que isso a ajudou muito, mas ressaltou que há diferenças de uma OLIVEIRA, D. G.; MOZZATO, A. R., COLET, D. S. Aprendizagem baseada em prática entre remédios e receitas em pequena farmácia. Revista de Empreendedorismo e Gestão de 
farmácia para outra. A Atendente 3 nunca havia trabalhado em uma farmácia, mas mostra-se empenhada e motivada para aprender. Tal aspecto foi observado em todos os trabalhadores da farmácia.

Quando questionados sobre como começaram a aprender as atividades da farmácia, as Atendentes 1, 2 e o proprietário citaram que foi junto à farmacêutica. Apenas a Atendente 3 citou que foi com as colegas atendentes, ficando evidenciado que há colaboração entre os trabalhadores. A farmacêutica falou de sua dificuldade inicial por não ter quem a ensinasse em seu local de trabalho:

Aprendi sozinha, pois no primeiro emprego trabalhei sozinha, não tinha ninguém comigo. E depois quando me tornei proprietária era só eu, não tinha ninguém para me auxiliar, então fui aprendendo, trabalhando mesmo, com experiência. Pesquisando em livros, internet [...]. Tudo o que tinha.

Esta fala pode ser relacionada com as ideias de Crossan, Lane e White (1999), quando expõem que o processo de intuição, que é individual, consiste no reconhecimento de um padrão que vem de dentro do indivíduo.

Fica evidenciado que há uma carência de busca por cursos técnicos e comportamentais por todos os trabalhadores da farmácia. Antonello e Godoy (2011) afirmam que a $\mathrm{AO}$ é estimulada pela necessidade de ajustamento a estímulos externos, entretanto, não se percebe este ajustamento quando o tema em questão é a aprendizagem fora da organização.

Dos cinco envolvidos, apenas a Atendente 2 encontra-se estudando, os demais não buscaram qualificação nos últimos tempos. As Atendentes 1 e 2 fizeram curso específico de atendente de farmácia, mas a Atendente 1 não buscou nada a mais. A Atendente 3 concluiu o Ensino Médio e não fez mais nenhum curso. Da mesma forma, os proprietários também não continuaram estudando após a conclusão das suas graduações.

Quando iniciaram no ramo farmacêutico, apenas o proprietário teve um treinamento específico sobre atendimento, mas as atendentes não tiveram nenhum. A farmacêutica conta que a sua experiência veio dos estágios, o que apenas lhe proporcionou algum conhecimento básico. Ela considera que a pessoa aprende mesmo é por meio da prática, no dia a dia, o que está em consonância com Gherardi (2009b, 2012), Antonello e Godoy (2011) e Rodrigues e Azevedo (2013). 
As atendentes concordam que a prática do dia a dia, a observação e a interação com outras pessoas do ramo são essenciais.

No entanto, todos entendem que leituras e buscas na internet como fonte de informações são importantes para a construção do conhecimento no cotidiano. Nesse sentido, fala a farmacêutica:

Como é medicamento, sempre está tendo medicamento novo, então não é uma coisa que tu pode parar no tempo, então toda a semana eles lançam um medicamento novo, laboratórios trocam de remédio, tipo o princípio ativo às vezes é o mesmo, mas o laboratório lança com um nome comercial diferente, então tu tem que estar sempre estudando. Hoje em dia o maior meio é a internet.

Portanto, percebe-se que os trabalhadores buscam formas distintas de aprendizado por meio da prática, isto é, por meio de mudanças no dia a dia, na troca de feedbacks, através de programas internos de treinamento, capacitação e expandindo conhecimentos. Importante destacar que a aprendizagem também se dá por meio da contratação de pessoas, que já possuam conhecimentos e habilidades, e a partir da aquisição e transferência de tecnologia nas atividades do dia a dia, ocorrendo a aprendizagem na prática no sentido defendido por Fleury e Fleury (1995) e Rodrigues e Azevedo (2013).

Dentre essas formas, pode-se observar que a prática é um dos aspectos mais consistentes no que se refere à aprendizagem, a qual é revelada nas falas e atitudes dos sujeitos da pesquisa.

Os feedbacks, apesar de citados pelos sujeitos e por serem importantes, não ficaram tão evidentes ao longo do processo da observação. Entretanto, o diálogo é recorrente, facilitando a troca de informações e o compartilhamento dos conhecimentos. Os entrevistados foram unânimes em afirmar que a troca de ideias é uma constante. O diálogo entre o grupo é algo bem marcante e perceptível, conforme a fala:

Eu acho que o diálogo né, as trocas [...] Por exemplo, quando chega um novo medicamento e a (Atendente 1) sabe mais, ela nos chama e explica, e às vezes, eu por ter trabalhado com médico, tem algumas coisas que eu sei que eu também falo pra elas: ah, eu fazia assim. Entende [...] (ATENDENTE $3)$.

OLIVEIRA, D. G.; MOZZATO, A. R., COLET, D. S. Aprendizagem baseada em prática entre remédios e receitas em pequena farmácia. Revista de Empreendedorismo e Gestão de Pequenas Empresas, v.5, n.3, 2016. 
Percebe-se que o grupo de trabalhadores da farmácia é unido e tem espírito de equipe fortalecido, compartilham ideias e estão à disposição para sanar dúvidas entre si. A Atendente 1, por ser a que está há mais tempo na função, mostra-se bem-disposta a ajudar as colegas e, quando percebe que alguma está com dúvidas ou "perdida", procura ajudar. Da mesma forma, a farmacêutica considera que a troca é muito importante, pois à medida que o conhecimento vai passando de uma para outra, faz com que a equipe cresça, se fortaleça, aprenda mais e, consequentemente, o atendimento será aprimorado e o cliente sairá mais satisfeito.

Este compartilhamento no âmbito das atividades é entendido como muito importante por vários autores, como Bastos, Gondin e Loiola (2004), quando afirmam que a $\mathrm{AO}$ começa a acontecer quando os integrantes da organização começam a dividir as suas práticas, disseminando e favorecendo 0 compartilhamento de estruturas cognitivas e de modelos interpretativos.

Percebe-se, ainda, na prática dos trabalhadores da farmácia uma tensão entre assimilar novos conhecimentos e usar o que aprenderam, como Behling e Eckel (1991 apud CROSSAN; LANE; WHITE, 1999) referem. Essa é a exploração descrita por Schikmann (2003), o qual afirma que essa tensão se constitui como um importante facilitador do processo de aprendizagem.

Extrapolando as fronteiras da farmácia, a farmacêutica menciona que quando surge alguma dúvida costuma procurar algum colega, conforme segue sua fala:

Quando as dúvidas surgem eu procuro ir para a internet, quando eu não consigo, eu procuro tirar com algum colega. Normalmente ligo para algum colega meu de trabalho, que também são farmacêuticos e podem auxiliar, por que, graças a Deus, me dou bem com os colegas. A Letícia (outra farmacêutica da cidade), por exemplo, me ajuda bastante [...] dessa maneira $[\ldots]$.

Tal atitude da Farmacêutica vai ao encontro do que Antonello e Godoy (2011) sustentam sobre as teorias baseadas em práticas, sendo que a aprendizagem não pode ser concebida como um processo apenas individual, e sim compreendida nas relações e interações das pessoas. Mais especificamente neste caso, há uma busca nos relacionamentos fora da farmácia, evidenciando a

OLIVEIRA, D. G.; MOZZATO, A. R., COLET, D. S. Aprendizagem baseada em prática entre remédios e receitas em pequena farmácia. Revista de Empreendedorismo e Gestão de Pequenas Empresas, v.5, n.3, 2016. 
ocorrência da AIO, no sentido defendido por Mozzato e Bitencourt (2014) e Mozzato, Bitencourt e Grzyboviski (2015).

Ficou claro que não há materiais estruturados quanto aos procedimentos da farmácia, mas tem o guia de medicamentos que ajuda bastante, especialmente para quem está iniciando, conforme afirma o proprietário. Ele revela ainda que no momento em que uma nova funcionária chega é feita uma explicação dos principais procedimentos da farmácia e que, normalmente, elas anotam e com o tempo aquilo vai se tornando normal.

Chegando ao final da análise multinível da $\mathrm{AO}$ na farmácia, numa tentativa de síntese, entende-se que a aprendizagem em nível individual começa a acontecer através da prática, com noções básicas que vão se aperfeiçoando. Em nível grupal, a aprendizagem se dá principalmente por meio do diálogo e trocas de informações, quando um colega ajuda o outro no dia a dia.

No que diz respeito à $A O$ observa-se que o resultado desta aprendizagem, que tem início na fase individual, passa para a fase grupal e torna-se um conhecimento organizacional. Isso é sustentado por Bastos, Gondin e Loiola (2004), ao afirmarem que a AO começa a acontecer quando os integrantes da organização começam a dividir suas práticas.

Por fim, a aprendizagem em nível interorganizacional ocorre por meio dos relacionamentos estabelecidos pela farmacêutica com colegas, outras farmácias e empresas de outros ramos, ou seja, por meio de relacionamentos além das fronteiras organizacionais.

\section{Categoria 2: Aprendizagem Baseada em Prática}

Nesta categoria são apresentados aspectos referentes à aprendizagem baseada na prática, citada como principal mecanismo que influencia o aprendizado. Apenas a Atendente 3 não confirmou esta forma como principal mecanismo de aprendizagem. Nesse sentido, refere o gestor: "se aprende fazendo, pois todos os dias a gente aprende muito". Gherardi (2001) conceitua a prática como a conexão entre o saber e o fazer.

OLIVEIRA, D. G.; MOZZATO, A. R., COLET, D. S. Aprendizagem baseada em prática entre remédios e receitas em pequena farmácia. Revista de Empreendedorismo e Gestão de Pequenas Empresas, v.5, n.3, 2016. 
Ficou nítida a importância da prática cotidiana na farmácia. Quando os sujeitos são questionados de que forma o conhecimento é absorvido, todos citaram a prática. O proprietário ainda citou o diálogo, o qual se dá no todo relacional do dia a dia. Seguem outras falas comprobatórias:

Na rotina do dia a dia é o que mais nos faz ter conhecimento, então mesmo quem ainda não absorveu todo o conhecimento, vai absorvendo aos poucos através da prática no dia-dia. (ATENDENTE 2). [...] a gente aprende através da prática. (ATENDENTE 3).

As informações obtidas nesta categoria permitiram perceber que os processos de formação dos trabalhadores nesta farmácia, bem como os mecanismos de aprendizagem, ocorrem por meio da prática, mesmo no caso da farmacêutica que possui Ensino Superior completo na área. O seu conhecimento também está apoiado na prática, desde o início de suas atividades como estagiária até o momento como proprietária. Tais atitudes vão ao encontro do que é defendido por Feitoza (2006) quanto ao trabalho na prática.

Mesmo os funcionários sem qualificação técnica específica conseguiram adaptar-se às atividades demonstrando que, apesar de importante, a formação na área não é limitante para a atuação na farmácia. As atividades diárias com base na repetição tornam-se fundamentais. Tais fatos vão ao encontro do que acreditam autores como Gherardi (2001), Antonello e Godoy (2011) e Rodrigues e Azevedo (2013).

Portanto, fica evidenciada a importância da prática no relacional do dia a dia para todos os níveis de aprendizagem. Em relação ao nível interorganizacional, Dierkes et al. (2001), Mozzato e Bitencourt (2014) e Mozzato, Bitencourt e Grzyboviski (2015), ao tratarem da necessidade das relações além das fronteiras organizacionais, evidenciam a prática como necessária. Estas relações (formais e informais) são observadas junto ao trabalho da farmacêutica com colegas formadas e outras farmácias, inclusive com as maiores para a obtenção de novas ideias (exposição de produtos, serviços diferenciados, etc.), que vão sendo implementadas na farmácia pesquisada.

OLIVEIRA, D. G.; MOZZATO, A. R., COLET, D. S. Aprendizagem baseada em prática entre remédios e receitas em pequena farmácia. Revista de Empreendedorismo e Gestão de Pequenas Empresas, v.5, n.3, 2016. 


\section{Categoria 3: Capacidade Absortiva}

A capacidade absortiva é muito importante para o processo da aprendizagem, pois na empresa é a soma das capacidades absortivas de seus trabalhadores. Para que a empresa absorva mais conhecimentos, ela deve ter uma base preliminar de conhecimento. Quando os participantes foram questionados se observam a concorrência a fim de melhorar os processos internos, no geral afirmaram não cuidar a concorrência dentro do município. Apenas a Atendente 2 informou que acha importante olhar para melhorar seu atendimento. Os proprietários afirmaram que, pelo fato da concorrência no ramo farmacêutico ser muito grande, eles observam as farmácias em cidades maiores, verificando o que fazem de diferente a fim de trazer novidades para a farmácia deles. A fala da farmacêutica confirma:

Eu não tenho o costume de cuidar o vizinho [...] por que eu acho que enquanto eu tô cuidando a farmácia do outro, eu tô perdendo o tempo de cuidar da minha [...] quando eu saio em outras cidades, uma cidade maior, eu procuro observar como eles estão fazendo para não parar no tempo... mas não na nossa cidade. Eu procuro quando eu saio para fora da cidade.

A fala da farmacêutica vai ao encontro do que Wegner e Maehler (2012) afirmam quanto à necessidade de as organizações valorizarem cada vez mais o conhecimento existente dentro ou fora da empresa, como um componente estratégico para o seu negócio. Associando o que os autores expõem e o que é desenvolvido na farmácia, observou-se que, em visita a uma farmácia de outro estado, trouxeram ideias que foram colocadas em prática dentro desta farmácia. Como exemplo, cita-se a confecção de kits para presentes, pois perceberam se tratar de uma prática interessante, os quais são vendidos em grande número semanalmente. Tal exemplificação ratifica o que afirma Daghfous (2004) quanto à capacidade absortiva, isto é, possibilita à empresa adquirir e utilizar de forma eficiente o conhecimento externo e interno, que são responsáveis pela habilidade da empresa para mudar e se modernizar a fim de permanecer competitiva.

OLIVEIRA, D. G.; MOZZATO, A. R., COLET, D. S. Aprendizagem baseada em prática entre remédios e receitas em pequena farmácia. Revista de Empreendedorismo e Gestão de Pequenas Empresas, v.5, n.3, 2016. 
Os proprietários informaram que buscam conhecimentos externos com ajuda de colaboradores e integrantes da rede (AIO), mas não estão participando ativamente dos eventos da rede, deixando de aproveitar as vantagens colaborativas das relações interorganizacionais. Tais vantagens são citadas tanto por Lane e Lubatkin (1998) como por Mozzato e Bitencourt (2014).

Apesar da não participação efetiva em eventos, tanto os proprietários como os trabalhadores reconhecem que a busca por qualificação deve existir constantemente, pois tende a agregar valor para os indivíduos e à empresa. Daghfous (2004) afirma que uma empresa que busca melhorar sua capacidade absortiva investe no desenvolvimento de seus trabalhadores por meio de atividades diversas, como capacitação profissional, não deixando de considerar que a $A O$ também representa um importante papel no desenvolvimento da capacidade absortiva.

Por meio da observação ficou evidenciado que os sujeitos da pesquisa têm vontade de aprender e percebem a necessidade de abertura ao novo. Exemplificando, apresenta-se a fala da Farmacêutica: "[...] a gente procura estar sempre buscando novas informações, estar melhorando nossos processos, por mais que ultimamente não tem sido muito fácil, não estamos investindo em capacitação formal".

Portanto, fica manifesto que a farmácia em estudo precisa valorizar continuamente os conhecimentos existentes, como afirmam Wegner e Maehler (2012). Neste sentido, Daghfous (2004) assegura que a base do conhecimento prévio é o primeiro fator a afetar a capacidade absortiva, visto que este fator depende de unidades individuais de conhecimento dentro da organização.

Observa-se que, mesmo com algum olhar às práticas externas e vontade de crescerem, os trabalhadores da farmácia poderiam utilizar mais da capacidade absortiva, pois deixam a desejar na busca de maiores conhecimentos que sejam úteis para a organização, inclusive por meio da própria rede de farmácias a qual pertencem. Tal fato impacta na falta de capacidade absortiva individual e, por consequência, organizacional, pois, conforme Cohen e Levinthal (1990), a capacidade absortiva organizacional depende da capacidade absortiva dos seus membros individuais.

OLIVEIRA, D. G.; MOZZATO, A. R., COLET, D. S. Aprendizagem baseada em prática entre remédios e receitas em pequena farmácia. Revista de Empreendedorismo e Gestão de Pequenas Empresas, v.5, n.3, 2016. 


\section{Considerações Finais}

Chegando ao final das análises desta pesquisa, entende-se que "entre remédios e receitas" foi possível uma maior compreensão do processo de aprendizagem em todos os níveis por meio do estudo de um caso na ótica da abordagem baseada em prática.

Nas análises das categorias constatou-se que na primeira, a aprendizagem em nível individual começa a acontecer através da prática, com as noções básicas que vão se aperfeiçoando. Em nível grupal, a aprendizagem se dá, principalmente, através do diálogo e trocas de informações quando um colega ajuda o outro. $\mathrm{Na} A O$, observa-se um resultado desta aprendizagem, que tem início na fase individual e, após, passa para a fase grupal, tornando-se um conhecimento organizacional. Quanto à $\mathrm{AIO}$, as trocas além das fronteiras da farmácia são evidentes e importantes para a aprendizagem e busca de vantagem competitiva.

As informações obtidas na segunda categoria permitiram perceber que os processos de formação dos trabalhadores desta farmácia, bem como os mecanismos de aprendizagem, ocorrem por meio da prática. Mesmo os funcionários sem qualificação técnica específica conseguiram adaptar-se às atividades da farmácia, demonstrando que, apesar de importante, a formação na área não é limitante para a atuação na farmácia.

$\mathrm{Na}$ terceira categoria observou-se que por mais que a capacidade absortiva fique evidenciada, poderia ser mais utilizada a fim de obter vantagem competitiva frente à concorrência. Percebe que os trabalhadores deixam a desejar na busca de maiores conhecimentos que sejam úteis para a organização.

Após essas análises "entre remédios e receitas", torna-se possível apresentar algumas sugestões pontuais para a farmácia: permanência do diálogo, pois ficou evidenciado que é um facilitador no processo da aprendizagem; elaboração de documentos/fluxogramas de atividades cotidianas, os quais vão servir, principalmente, para os novos funcionários; busca de mais relações externas, que culminam em maior aquisição de conhecimento. Tais buscas podem ser

OLIVEIRA, D. G.; MOZZATO, A. R., COLET, D. S. Aprendizagem baseada em prática entre remédios e receitas em pequena farmácia. Revista de Empreendedorismo e Gestão de Pequenas Empresas, v.5, n.3, 2016. 
realizadas por meio de eventos da própria rede de farmácias, além da participação em congressos, visitas a outras farmácias e observações sobre a concorrência.

Assim, além da aplicabilidade prática no campo empírico da pesquisa, entende-se que este artigo traz uma contribuição muito mais ampla para o campo de pesquisa sobre a aprendizagem em seus diferentes níveis em uma perspectiva sociológica. Ratifica-se tal contribuição justamente pelo fato de se trabalhar na perspectiva multinível da aprendizagem e baseada em prática, explicitando com maior clareza o tema, o qual é complexo e relevante para a atual e futuras agendas de pesquisas.

De tal modo, o estudo de caso da realidade de uma pequena empresa de cunho familiar pode servir de inspiração para a aplicabilidade prática e avanço teórico sobre a aprendizagem também relacionada a pequenas e médias empresas. Por fim, busca-se incentivar pesquisas futuras, principalmente as empíricas e com abordagem metodológica qualitativa, sob perspectivas de análises menos positivistas sobre a temática aqui trabalhada.

\section{Referências:}

ANTANACOPOULOU, E. Desenvolvendo gerentes aprendizes dentro de organizações de aprendizagem. In: EASTERBY-SMITH, M.; BURGOYONE, J.; ARAUJO, L. Aprendizagem Organizacional e Organização de Aprendizagem. São Paulo: Atlas, 2001.

ANTONACOPOULOU, E. P. The relationship between Individual and Organizational Learning: New Evidence from Managerial Learning Practices. Management Learning, v. 37, n. 4, p. 455-473, 2006.

ANTONELLO, C. S.; GODOY, A. S. A encruzilhada da Aprendizagem Organizacional: uma visão multiparadigmática. Revista de Administração Contemporânea, v. 14, n. 2, p. 310-332, 2010.

Aprendizagem organizacional no Brasil. Porto Alegre: Bookman, 2011.

BARDIN, L. Análise de conteúdo. Lisboa: Edições 70, 2006.

BASTOS, A. V. B.; GONDIN, S. M. G.; LOIOLA, E. Aprendizagem organizacional versus organizações que aprendem: características e desafios que cercam essas duas abordagens de pesquisa. Revista de Administração da Universidade de São Paulo, v. 39, n. 3, p. 220-230, 2004.

OLIVEIRA, D. G.; MOZZATO, A. R., COLET, D. S. Aprendizagem baseada em prática entre remédios e receitas em pequena farmácia. Revista de Empreendedorismo e Gestão de Pequenas Empresas, v.5, n.3, 2016. 
BILLETT, S.; HARTEIS, C.; GRUBER, H. International Handbook of Research in Professional and Practice-based Learning. Dordrecht: Springer, 2014.

BITENCOURT, C. C. A gestão de competência gerenciais - a contribuição da aprendizagem organizacional. 2001. 319f. Tese (Doutorado em Administração) Escola de Administração, Universidade Federal do Rio Grande do Sul, Porto Alegre, 2001.

BISPO, M. S. Aprendizagem organizacional baseada no conceito de prática: contribuições de Silvia Gherardi. Revista de Administração Mackenzie, v. 14, n. 6, p. 132-161, 2013.

COHEN, W. M.; LEVINTHAL, D. A. Absorptive capacity: A new perspective on learning and innovation. Administration Science Quarterly, v. 1, n. 34, p. 128-152, 1990.

CORRADI, G.; GHERARDI, S.; VERZELLONI, L. Through the practice lens: where is the bandwagon of practice-based studies. Management Learning, v. 3, n. 41, p. 265-283, 2010.

CROSSAN, M. et al. Organizational learning: Dimensions for a theory. The International Journal of Organizational Analysis, v. 3, n. 4, p. 337-60, 1995.

CROSSAN, M; LANE, H; WHITE, R. An organizational learning framework: from intuition to institution. The Academy of Management Review, v. 24, n. 3, p. 522537, 1999.

; MAURER, C. C.; WHITE, R. E. Reflections on the 2009 AMR decade award: do wehave a theory of organizational learning? The Academy of Management Review, v. 36, n. 3, p. 446-460, 2011.

CRUZ, M. A. Mensuração da capacidade absortiva dos parceiros industriais da Cemig: implicações para inovação no setor elétrico. 2011. 188f. Dissertação (Mestrado em Administração). Escola de Administração, Pontifícia Universidade Católica de Minas Gerais, Belo Horizonte, 2011.

DAGHFOUS, A. Absorptive capacity and the implementation of knowledge-intensive best practices. Advanced Management Journal, v. 2, n. 69, p. 21-27, 2004.

DENZIN, N. K.; LINCOLN, Y. S. Handbook of Qualitive Research. 2. ed. Thousand Oaks: Sage, 2000.

DIERKES, M. et al. Handbook of Organizatinal Learning and Knowledge. New York: University Press, 2001.

DODGSON, M. Organizational learning: a review of some literatures. Organization Studies, v. 14, n. 3, p. 375-394, 1993.

OLIVEIRA, D. G.; MOZZATO, A. R., COLET, D. S. Aprendizagem baseada em prática entre remédios e receitas em pequena farmácia. Revista de Empreendedorismo e Gestão de Pequenas Empresas, v.5, n.3, 2016. 
EASTERBY-SMITH, M.; BURGOYNE, J.; ARAUJO, L. Aprendizagem Organizacional e Organização de Aprendizagem: desenvolvimento na teoria e na prática. São Paulo: Atlas, 2001.

EASTERBY-SMITH, M.; LYLES, M. The blackwell handbook of organizational learning and knowledge managemet. Oxford: Blackwell Publishing, 2003.

FEITOZA, J. S. O. et al. A contribuição do estudo da aprendizagem organizacional para os gestores de empresas. In: SIMPEP, 13, 2006, Bauru. Anais... Bauru, 2006.

FLACH, L.; ANTONELLO, C. Organizações culturais e a aprendizagem baseada em práticas. Cadernos EBAPE, v. 9, n. 1, p. 156-175, 2011.

FLEURY, A. C. C.; FLEURY, M. T. L. Aprendizagem e inovação organizacional: as experiências de Japão, Coréia e Brasil. 2. ed. São Paulo: Atlas, 1995.

FLICK, U. Introdução à pesquisa qualitativa. 3. ed. São Paulo: Artmed, 2009.

GHERARDI, S. From organizational learning to practice-based knowing. Human Relations, v. 54, n. 1, p. 131-139, 2001.

. Organizational Knowledge: The Texture of Workplace Learning. Oxford: Blackwell Publishing, 2006.

Situated knowledge and situated action: what do practice-based studies promise? In: BARRY, D.; HANSEN, H. New approaches in management and organization. London: SAGE, 2008.

. Introduction: the critical power of the "practice lens". Management Learning, v. 40 , n. 2, p. 115-128, 2009a. 2009b.

Practice? It's a matter of taste! Management Learning, v. 40, n. 5, p. 535-550,

How to conduct a practice-based study. Cheltenham: Edward Elgar, 2012.

To start practice theorizing anew: The contribution of the concepts of agencement and formativeness. Organization, n. 22, p.1-19, 2015.

GHERARDI, S.; NICOLINI, D. The sociological foundations of organizational learning. In: DIERKES, M. et al. (Org.) Organizational learning and knowledge. Oxford: Oxford University Press, 2001. p. 35-60.

GHERARDI, S.; NICOLINI, D.; ODELLA, F. Toward a social understanding of how people learn in organizations: the notion of situated curriculum. Management Learning, v. 29, n. 3, p. 273-297, 1998.

OLIVEIRA, D. G.; MOZZATO, A. R., COLET, D. S. Aprendizagem baseada em prática entre remédios e receitas em pequena farmácia. Revista de Empreendedorismo e Gestão de Pequenas Empresas, v.5, n.3, 2016. 
GHERARDI, S.; SOUTO, P. C. N. What do people do when they work? The contribution of practice-based studies to the understanding of working and organizing. In: ENCONTRO DA ANPAD - EnAnpad, 37, 2013, Rio de Janeiro. Anais... Rio de Janeiro, 2013.

GREVE, H. R. Inter-organizational learning and social structure. Organization Studies, v. 26, p. 1025-1047, 2005.

INKPEN, A. C. Learning and knowledge acquisition through international strategic alliances. Organization Science, v. 9, n. 4, p. 454-468, 1998.

KNIGHT, L. Network learning: Exploring learning by interorganizational networks. Human Relations, v. 55, n. 4, p. 427-454, 2002.

KNIGHT, L.; PYE, A. Network learning: An empirically derived model of learning by groups of organizations. Human Relations, v. 58, n. 3, p. 369-392, 2005.

LANE, P. J.; LUBATKIN, M. Relative absorptive capacity and interorganizational learning. Strategic Management Journal, v. 19, n. 5, p. 461-477, 1998.

LARSSON, R.; BENGTSSON, L.; HENRIKSSON, K.; SPARKS, J. The Interorganizational Learning Dilemma: Collective Knowledge Development in Strategic Alliances. Organization Science, v. 9, n. 3, p. 285-305, 1998.

LAVE, J.; WENGER, E. Situated learning: legitimate peripheral participation. Cambridge: Cambridge Press, 1991.

MOZZATO, A. R.; BITENCOURT, C. C. Understanding Interorganizational Learning Based on Social Spaces and Learning Episodes. BAR - Brazilian Administration Review, v. 11, n. 3, p. 284-301, 2014.

MOZZATO, A. R.; BITENCOURT, C. C.; GRZYBOVSKI, D. The Interorganizational Level in the Learning Continuum: Analytic Conceptual Scheme. International Business Research, v. 8, n. 4, p. 94-106, 2015.

MOZZATO, A. R.; GRZYBOVISKI, D. Análise de conteúdo como técnica de análise de dados qualitativos no campo da administração: Potencial e desafios. Revista RAC, v. 15, n. 4, p. 731-747, 2011.

NICOLINI, D.; GHERARDI, S.; YANOW, D. Knowing in organizations: a practicebased approach. Nova York: M. E. Sharpe, 2003.

NOGUEIRA, R. A.; ODELIUS, C. C. Desafios da Pesquisa em Aprendizagem Organizacional. Cadernos EBAPE, v. 13, n. 1, p. 83-102, 2015.

OLIVEIRA, D. G.; MOZZATO, A. R., COLET, D. S. Aprendizagem baseada em prática entre remédios e receitas em pequena farmácia. Revista de Empreendedorismo e Gestão de Pequenas Empresas, v.5, n.3, 2016. 
RODRIGUES, B.; AZEVEDO, D. Entre facas e chairas - Um estudo sobre a aprendizagem baseada em prática de açougueiros. Desenvolve: Revista de Gestão da Unilasalle, v. 2, n. 2, p.117-136, 2013.

SCHIKMANN, R. Características de uma Organização de Aprendizagem: pesquisa em uma empresa brasileira. 2003. 139f. Dissertação (Mestrado em Administração) EAESP/FGV, São Paulo, 2003.

WEGNER, D. Aprendizagem interorganizacional: um estudo das redes horizontais de pequenas empresas. In: ANTONELLO, C. S.; GODOY, A. S. (Eds.). Aprendizagem organizacional no Brasil. Porto Alegre: Bookman, 2011. p. 89-113.

WEGNER, D.; MAEHLER, A. E. Desempenho de empresas participantes de rede interorganizacionais: analisando a influência do capital social e da capacidade absortiva. Revista Gestão e Planejamento, v. 13, n. 2, p. 191-211, 2012.

YIN, R. K. Estudo de caso: planejamento e métodos. 3. ed. Porto Alegre: Bookman, 2005.

ZANGISKI, M. A. S. G.; LIMA, E. P.; COSTA, S. E. G. Aprendizagem organizacional e desenvolvimento de competências: uma síntese a partir da gestão do conhecimento. Revista Produto \& Produção, v. 10, n. 1, p. 54-74, 2009.

i Este artigo foi aprovado por ser proveniente do fast track Egepe 2016 e por ter apresentado as alterações sugeridas pelos avaliadores do evento.

OLIVEIRA, D. G.; MOZZATO, A. R., COLET, D. S. Aprendizagem baseada em prática entre remédios e receitas em pequena farmácia. Revista de Empreendedorismo e Gestão de Pequenas Empresas, v.5, n.3, 2016. 